\title{
Generating electric vehicle load profiles from empirical data of three EV fleets in Southwest Germany
}

\author{
Johannes Schäuble ${ }^{\mathrm{a}, *}$, Thomas Kaschub ${ }^{\mathrm{a}}$, Axel Ensslen ${ }^{\mathrm{a}}$, Patrick Jochem ${ }^{\mathrm{a}}$, \\ Wolf Fichtner ${ }^{\mathrm{a}}$ \\ ${ }^{a}$ Chair of Energy Economics, Karlsruhe Institute of Technology, Hertzstr. 16, D-76187 \\ Karlsruhe
}

\begin{abstract}
The increasing demand for electricity caused by a growing number of electric vehicles $(\mathrm{EV})$ is a major challenge for future energy systems. For an integration of the electricity demand from EV, a comprehensive knowledge of its characteristics is essential. The analysis of charging behavior patterns of EV and resulting load profiles become important premises for this crucial task. Three electric mobility studies in Germany's southwestern region (Get eReady, iZEUS, and CROME) deliver comprehensive data of EV use for this purpose. In this paper we analyze and discuss the mobility and charging characteristics of this data in detail. We derive empirical EV load profiles and show how they are affected by charging management as well as charging power. We present a model to simulate EV loads based on statistical characteristics of the conducted studies. The resulting charging load profiles show similar patterns as other EV studies. The developed simulation model and its results (see supplementary data available online) allow a realistic
\end{abstract}

\footnotetext{
${ }^{*}$ Corresponding author: Johannes Schäuble, Hertzstr. 16, D-76187 Karlsruhe; E-mail: schaeuble@kit.edu; Phone: +49 72160844501
} 


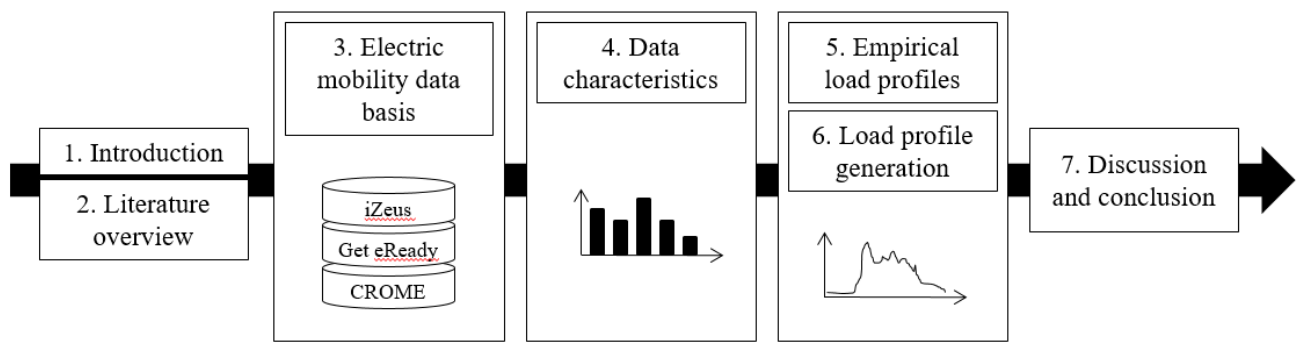

Figure 1: Graphical abstract

representation of EV demand in analyses of future energy systems.

\section{Introduction}

An increasing demand for energy, and electricity in particular, decreasing fossil energy source stocks and the necessity to act against climate change leads to a multitude of new policy objectives and measures. Supporting electric mobility is a major objective and leads to a shift from oil to electricity as an energy carrier particularly in the private transport sector. This will increase the impact of the transport sector on electricity systems. Yet, the current share of electric vehicles (EV) in Germany and most other countries is relatively low (below $1 \%$ in January 2015 (EVI-IEA, 2016)). In consequence there is currently no demand for EV load forecasting by electricity suppliers (Linssen et al., 2009). However, various forecasts assume a rapidly increasing share of EV in the private transportation sector (e. g. Kieckhäfer et al. (2016)). In future, the energy system has to cope with this additional load. This adaptation requires precise forecasts of the load caused by electric mobility. Charging can only be controlled and regulated based on a good 
knowledge of future electric mobility pattern. This knowledge will enable the full potential of possible grid services (Habib et al., 2015) and market supporting measures (Drude et al., 2014). These measures are highly relevant in the context of energy transition and concomitant increase in renewable electricity generation (REG) as well as decentralized generation in general.

To address this need, this paper provides load profiles and a model for generating synthetic load profiles that are based on real EV mobility and charging data of three mobility studies with a total of about 30,000 recorded charging operations by more than $400 \mathrm{EV}$. To be able to fully understand the nature of the EV load we give detailed insights into characteristics of the underlying EV mobility data. As a consequence we give answers to the following research questions: (i) How can EV mobility and charging data be processed to create descriptive EV load profiles and what are the characteristics of these EV load profiles? (ii) How can EV load profiles be simulated using empirical charging data? (iii) What are the characteristics of these simulated EV load profiles?

The complete approach of this paper is shown in fig. 1. In a first step we give a literature overview of existing analyses of EV fleet studies, the subsequent performed simulation of EV load profiles and their applications (c.f. part 2). Following, the data basis from three field trials (c.f. part 3) and their statistical characteristics, filtering and preparation of these data sets (c.f. part 4) are addressed. Based on these data sets a subsequent empirical load profiles for various scenarios are derived (c.f. part 5). Moreover, the used methods and assumptions for the load profile generation are discussed. Subsequently, we present the simulation model that allows generating weekly 
or daily charging load profiles for a given number of EV based on the presented EV mobility data (c.f. part 6). The paper concludes by comparing the results with findings from other studies as well as validating and critically assessing the overall results of this paper (c.f. part 7).

\section{Literature overview}

Before presenting our EV load simulation model, its underlying data and studies that provided data we give an overview on EV load studies. First we discuss other EV field tests and their characteristics. Subsequently, we focus on the generation of EV load profiles and look into approaches of how to simulate EV loads at different aggregation levels. Finally, we give an overview on analyses that use simulated EV loads to study the impacts of EV on energy systems.

\subsection{EV fleet studies}

Driven by the political goal to decrease (local and global) emissions of the transportation sector vehicle manufacturers started to push development of EV since 2010 (EVI-IEA, 2016). First battery electric vehilces (BEV) and plug-in hybrid electric vehicles (PHEV) were already available on the market. Models of large original equipment manufacturers (OEM) followed. Correspondingly the need for field fleet tests that studied EV, their users, necessary context of electric mobility and impacts of this new technology increased. Often, installation of public and private charging infrastructure accompanied these field tests. A multitude of EV fleet tests has been performed worldwide. Instead of entering into details of various studies we refer to review papers and studies treating a multitude of fleet tests: Hildermeier 
(2016) compares all EV projects co-funded by the European Union between 2007 and 2013 showing that solely few projects created new or alternative mobility patterns instead of basing their research on conventional mobility. Leurent and Windisch (2011) give an overview on Londons EV delivery plan, Germany's model regions and the project VLOTTE in Austria concluding that public policy intervention but also technical, industrial and economic factors have great influence on electric mobility. Corchero Garcia et al. (2014) provides information on the green eMotion project, that gathered data from several EV fleet studies all over Europe. This allowed them to detect that EV ownership and usage are crucial input parameters for studies on electric mobility. Additionally they proved that locations of charging stations influence charging behavior like parking times, charging durations and consumed energy. Smart et al. (2013) give insights into early results of an EV project conducted in 18 US cities deploying about 12,500 public and residential charging stations and 8,650 PHEV. In their analysis they identified a potential of driving in electric mode for PHEV of $73 \%$ (assuming a fixed electric range of $55 \mathrm{~km}$ ) based on driving and charging behavior.

\subsection{Synthetic EV load profiles}

A multitude of simulation models of EV load profiles use for their analysis representative mobility data of conventional vehicles or general mobility patterns. The German Mobility Panel (MOP, BMVBS (2010)) and the Mobility in Germany study (MiD, Lenz et al. (2010)) are databases that allow to deduce EV charging behavior of German households. Motor Traffic in Germany (KiD) focuses on German commercial mobility. Similar studies are available for other countries, for example the national survey on transport 
and travel (ENTD) for France (Windisch, 2014), the study of the Austrian motorized individual mobility (Litzlbauer, 2010) the Regional Travel Household Interview Survey (RTHIS) and the 2000 Census Transportation Planning Package (CTPP) for the US. Pasaoglu et al. (2013) compare simulated EV load profiles of six European countries based on different mobility data sources. These studies have oftentimes been used to deduce EV charging load profiles (e. g. Babrowski et al. (2014)). However, results and conclusions of these studies lack EV specific mobility characteristics. Few simulations of EV load profiles actually base their models on real EV charging data. One example is shown by Wieland et al. (2015) who use data from charging stations in Graz (E-mobility Graz, 2013) to model charging behavior of EV under consideration of locations. The simulations by Wieland et al. (2015) provide information on the expected energy usage, locations and number of electric charging stations.

\subsection{Applications of the synthetic EV loads}

The EV load profile generated can be used to analyse the impact of EV charging activities on a specific electricity system or the energy system in general (e. g. Mills and MacGill (2014)). Making use of charging flexibility and load shift potentials of EV, charging requires intelligent and controlled charging (Hahn et al., 2013). With more knowledge on EV (and their batteries) models using the simulated EV loads may focus on optimal integration into day-ahead and real-time wholesale energy markets (Valentine et al., 2011) for example by using the vehicle to grid (V2G) functionality (Loisel et al., 2014). Further analyses make assumptions concerning mobility behavior and use normally distributed parameters. They rather put their 
focus on optimal charging control than realistic detailed EV charging data (e. g. Ahn et al. (2011)). However, when looking at applications of simulated EV loads for further analysis in a large part of literature underlying input data for EV load profiles is not transparent and mainly derived from general, conventional mobility patterns.

\section{Electric mobility data basis}

An appropriate and comprehensive data basis is necessary to analyze electric mobility charging behavior and allows developing an extensive model to generate EV charging load profiles. As explained before, using general (conventional) mobility data requires assumptions on the characteristics of charging processes (e. g. locations, behavior, active power or driving efficiency) which may reduce the quality of the result. To minimize these assumptions, the following analysis and simulations use primary EV mobility and charging behavior data of three field trials conducted in Southwest Germany. Each field trial was part of a mobility project. Each was conducted by a consortium of industry and research partners. To give an overview on the different trials' contexts and their data collection approach, scope and quality they are briefly described in the following three subsections.

\subsection{Cross border mobility for electric vehicles (CROME)}

The project CROME was a French-German project carried out between 2011 and 2013 funded by federal ministries of both countries (Schäuble et al., 2016b). Aim of the project was to design, enable and analyze border-crossing, secure, user-friendly and reliable electric mobility between France and Germany. More than $100 \mathrm{EV}$ were part of the CROME field trial, equipped with 
on-board data loggers and smartphones to track mobility behavior of the EV users. The on-board data loggers installed by the OEM recorded technical data during the trips and during the charging processes. In addition, smartphones distributed to the EV users permitted to track the trips via GPS and to add meta data via a questionnaire for e. g. the purpose of the trip on a voluntary basis. Most of the cars were part of company car fleets and were used by several users. In the field trial several EV models were used: 53 Smart fortwo electric drive phase two (Smart ed2), seven Renault Kangoo Z.E., 11 Peugeot iOn/Citron C-ZERO. Additionally two prototype Porsche Boxster e, three Porsche Panamera S Hybrid and four Toyota Prius Plug-In Hybrid were part of the fleet. In total 3,160 valid charging events where recorded and extracted from the collected data in CROME.

\subsection{Intelligent Zero Emission Urban System (iZEUS)}

The project iZEUS conducted between 2012 and 2014 had the aim to develop recommendations to promote standardization for energy and charging management of EV. Several different field trials and data collecting methods were used. Over 50 mainly privately used Smart fortwo electric drive phase three (Smart ed3) and six PHEV (five Toyota Prius and one Opel Ampera) as well as few other cars like commercial Mercedes Benz Vito E-CELL took part in the field trial. The cars were equipped with on-board data loggers and tablets that were used to track GPS data and get user information. Additional e-Bike field trials with students were performed and real-user experiences of controlled discharging and vehicle-to-home at the KIT energy smart home lab (ESHL) with an Opel Meriva EDI analyzed. However, the e-bike and ESHL data are not part of this analysis. All participants of the 
field trials were equipped with tablets which could be used on a voluntary basis. The tablets provided a routing application including special EV features. Also trip tracking based on GPS location was included and a short user questionnaire before and at the end of the trip for additional meta trip data was provided by the drivers. All smart ed3 were equipped with on-board data loggers which collected data at each trip start, trip end, charging start and charging end. The field trial was conducted over a period of one year (though some participants joined the field test later). 6,088 valid charging events were recorded and extracted.

\subsection{Operator model for electric fleets in Stuttgart (Get eReady)}

In the framework of the project Get eReady funded by the Federal Ministry for Economic Affairs and Energy a large-scale fleet trial including 109 organizations, $327 \mathrm{EV}$ and a regional charging network with 181 connected charging points was set up between 2013 and 2015 in order to analyze success factors for EV adoption of organizations in the south-western part of Germany. The organizations participated in the project between 7 and 27 months, 16 months on average. They received a monthly compensation of expenses for participating, for the still existing economic disadvantages of EV and for providing data on charging events within the projects charging network. $75 \%$ of the participating organizations were small and medium-sized companies. Further information characterizing the fleet test participants is available in Ensslen et al. (2016a). Information on the charging events were automatically recorded in the charging points and saved in the charging infrastructure backend. Between November 2013 and December 2015 19,696 charging events with 344 different EV drivers (identified by RFID cards) 
of which 288 could be attributed to specific EV were recorded. 21 different types of EV models were used by the participating organizations and charged at 155 different charging locations.

\subsection{Consequential empirical data basis}

The different data collection approaches of the fleet tests resulted in differences concerning data formats, file types, content, quality and reliability. The different data sets available consist of vehicle trip data and electric vehicle supply equipment (EVSE) log data in different resolutions (e. g. 5 s, 5 min, per event, per trip, per $50 \mathrm{~W}$ ). Additionally, not all information were available for every charging event (e. g. locations in categories or via GPS, parking times only available for $90 \%$ of the data sets). Where possible faulty data sets have been corrected, otherwise ignored. In total 29,262 valid charging events were used for the following analyses and as input for simulating EV charging load profiles. A single data set represents a single charging event. During the event the charging may be interrupted, however the vehicle remains plugged-in and unmoved. We distinguish the data according to the following three groups which had to be prepared differently:

- Continuous: Data with continuous measurements (e. g. state of charge (SOC)) during charging process with a sufficiently high time resolution.

- Basic: Data includes the SOC values $\left(S O C_{\text {init }}\right.$ and $\left.S O C_{\text {end }}\right)$ for charging start time $t_{c, \text { init }}$ and end time $t_{c, \text { end }}$.

- Basic+Parking: Additional the starting time and end time for parking $\left(t_{p, \text { init }}\right.$ and $\left.t_{p, \text { end }}\right)$ are given. 
Continuous measurements include values for each single timestamp. This results in time series with a multitude of timestamp entries for each charging process. The time series had to be checked for inconsistencies (e. g. false timestamps or SOC values). Subsequently we reduced the data volume to the necessary scope and removed faulty entries. Some of the time series of the CROME Kangoo vehicles had to be treated individually. Charging times had to be adjusted (reduced) to the times with SOC entries which were in some few cases incomplete. These adjustments reduced the charging times by some minutes and depth of charging slightly. We did not extrapolate the SOC values in these cases. Few of the resulting charging processes were fragmentary, nevertheless included into the further analyses. The continuous time series allow to evaluate the charging processes concerning active power charging curves with a high time resolution (s. part 5.2).

Data collections of basic charging events solely include information on start and end times as well as SOC of the charging processes. They do not include additional data collected during the charging processes. Additional assumptions to deduce corresponding charging load profiles are in these cases required. The basic charging data had to be checked for inconsistencies (e. g. $S O C_{\text {init }}<0 \%, S O C_{\text {end }}>100 \%$ or missing values). We removed data sets with false measured values. As parking times were not implied in most of the data collections, we deduced them from the end time of the previous trip and the starting time of the following trip. Inconsistencies were handled as follows. If the following trip started less than 5 minutes before the end of the charging process, we used the start of the following trip as $t_{c, \text { end }}$ and $t_{p, e n d}$. If several charging events occurred before a following trip 
the parking time was merged to an aggregated charging of all single charging processes. These assumptions (concerning inconsistent times) were used for other data sets including parking times as well. To harmonize the data collections, we extracted the necessary information of start and end times including SOC values from the continuous charging data. Few temporal inconsistencies appeared as a single offset within a charge. All subsequent lines may have an incorrect time stamp. Correction of such errors have been dispensed. As a result, these charging processes are partially incomplete. Due to this, the filtering was carried out primarily according to the measured difference between the initial SOC and final SOC value: If the fraud was below $1 \%$ or more than $100 \%$, the corresponding charging process was discarded. The same applied to incomplete or inconsistent charging data. The duration of a charging operation was not explicitly given in some cases, but was calculated using the time difference between two days. If this resulted in a trip starting during a charging process the data set was neglected for the analyses. Multiple charges during one parking period were aggregated.

\section{Data characteristics}

In the following section we present the analyzed electric mobility patterns - especially the charging behavior - based on the previously presented data basis (c.f. section 3). First we briefly highlight general characteristics of the data. If the time resolution $h$ of the following analysis is lower than the granularity of the survey data (e. g. $h=1 h$ ) the average value of the corresponding parameter for the time slot between $t-h$ and $t$ is used. Some data specifications are not available within all data sources (e. g. no implicit SOC values for the get eReady data), in this case the analyses refer to the 
data subset (indicated by the total number $n$ ) that contains the necessary data. Second, specific and extensive insights into charging behavior during the day follow. We used Matlab ${ }^{\circledR}$ R2015b in connection with a MySQL Database for data processing.

\subsection{General charging behavior characteristics}

The first charging operation was recorded on the 3rd November, 2011 the last on the 31st December, 2015 (1,519 days). During this period the number of active

(i.e. recorded and regularly charging) EV varied (c.f. fig. 2, top). From the 31st January, 2013 until the end of the recording period more than $15 \mathrm{EV}$ were permanently active. Recorded charges increase with the number of active EV, however a fluctuating charging behavior can be observed (c.f. fig 2, center and bottom). Effects of different sudies' time periods are likely to be marginal compared to differences of the field tests. For example MiD 2002 and MiD 2008 differ little, whereas there are larger differences between KiD and $\mathrm{MiD} / \mathrm{MOP}$.

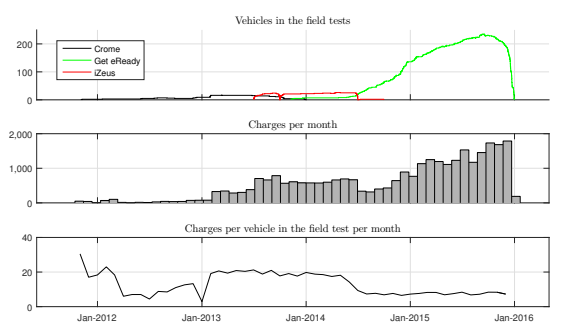

Figure 2: Number of active EV (top), charging processes per month (center) and charges per EV and month (bottom)

The weekly distribution of charging operations (c.f. fig. 3) shows a relatively constant level of 15 to $20 \%$ for all the studies during the weekdays 
(Mon.-Fri.). However, the share of EV charging at the weekend is significantly lower.

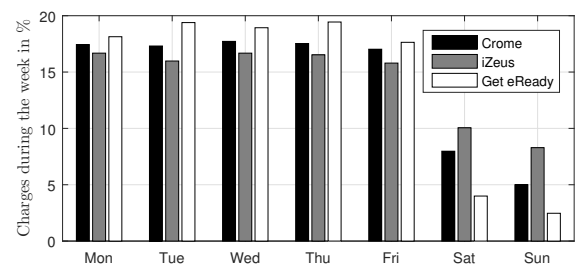

Figure 3: Percentage of charging processes per weekdays

Average values on charging processes per weekday (Charging processes per weekday in average are: Mon: 0.35; Tue, Wed, Thu: 0.37; Fri: 0.34; Sat: 0.11; Sun. 0.08) indicate that the EV are not charged equally distributed over the week. For data originating from charging stations it has to be considered that users may have charged at charging points that were not part of the fleet test. Additionally, few vehicle were parked for longer periods, i. e. 1-2 weeks which reduces the average. An EV is on average charged every third to fourth day (0.2857 times per day). The EV are charged significantly less often on weekends. When charged during a day, the EV are usually not charged any more at the same day (c.f. fig. 4). To calculate the days without a charging event, we assumed a vehicle to be in (fleet-)usage from its first to the last recorded charging event (c.f. fig 2, bottom). However, charging operations may not have been registered, which leads to an understated number of the actual charging events per day.

Observations of the studies' data indicate a change of the charging behavior over a longer period. Fig. 4 shows the changes of charging behavior indicated by the average number of charges per day at which a vehicle was 
charged for the observed years. As shown in fig. 2 starting in last quarter of 2011 only few vehicles were recorded for which reason 2011 is not shown in fig. 4 for reasons of comparability. The average number of charges per day decreased over the years for most of the days of the week, although some new participants entered the fleet trials belatedly and the fleet tests started at different times. This may lead to the assumption that EV users charged their vehicles less often with an increasing holding period of their EV. The allover mean values for all years and weekdays are the following:

1. The mean charging events per vehicle and per day at which a vehicle charges is at $\overline{l p}_{h=24 h}=1.5378$ (cf. table 2).

2. The mean of all vehicles' mean charging events per day at which at least one vehicle was charged is at 1.3788. When taking into account the days when no vehicle was charged,

3. the mean of the charging events per vehicle and per day is at 1.2947.

4. The mean of all vehicles' mean charging events per day is at 0.2857 .

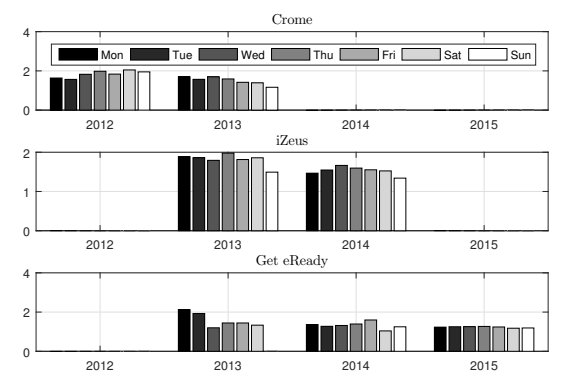

Figure 4: Yearly variation of the average number of charges per vehicle and weekday (at which the vehicle was charged) 


\subsection{Charging locations}

Some of the data sets include information on the parking location (e. g. iZEUS via tablet, Get eReady via location of the charging station) which can be classified in categories (like private or company). Fig. 5 illustrates the main parking locations during the day which are private parking locations especially during nighttimes (about $60 \%$ ) and parking at the company during working hours. Public parking is used less often but still has a share of over $15 \%$ during the whole day. In combination with the available charging infrastructure and their characteristics (e. g. maximum power, cf. part 6.4) this data allows to analyse and simulate EV charging load profiles.

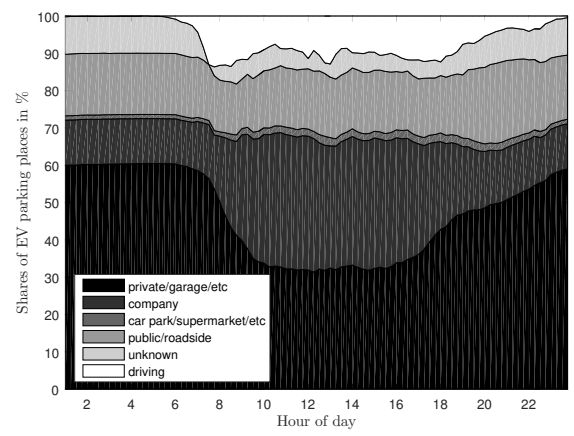

Figure 5: Shares of EV parking places during the course of the day, data gathered with tablets in the iZeus project

\subsection{State of charge}

The composition of the values for the SOC at the beginning of the charging operation $\left(S O C_{\text {init }}\right)$ differs in the course of a day (c.f. fig. 6). The low number of observed charging starts during the night imply a limited validity concerning inference for these hours. Aggregating the values provides a better indication and leads to a median of $q_{0.5}=58.8 \%$ for the $S O C_{\text {init }}$ 
values from midnight to 5 a.m. $(\mathrm{n}=141)$, and to $q_{0.5}=66 \%$ from 23 p.m. to 6 a.m. $(\mathrm{n}=321)$. The $S O C_{\text {init }}$ are in general lower in the morning (from 7 to 9 a.m.) and during the night (aggregated periods). In contrast, the SOC at the end of the charging operations $\left(S O C_{\text {end }}\right)$ (c.f. fig. 7$)$ show no significant dependence to the time of day and are throughout high. Slightly lower quartiles $\left(q_{0.25}=76.5 \%\right.$ from 8 to 9 a.m. $)$ can be observed in the morning and afternoon. However, values of the $S O C_{\text {end }}$ are distributed to a greater extend in each hour than $S O C_{\text {init }}$ (e. g. in the period from 6 a.m. to midnight the standard deviation $\sigma\left(S O C_{\text {init }}\right)$ is $14.2 \%$ compared to $\sigma\left(S O C_{\text {end }}\right)$ of $\left.24 \%\right)$.

\subsection{Time of charging}

The number of starting charging operations varies over a day and is shown in fig. 6. Merely $1.8 \%$ of the charging operations are initiated between midnight and 6 a.m. Beginning at 6 a.m. the number of charging events increases. Peaks can be observed in the early morning between 7-8 a.m., the late morning between 10-11 a.m. and from 1-2 p.m. when about $10 \%$ of all charges are initiated. During the afternoon the numbers stay high with a peak in the evening from 5-6 p.m. and following decreasing numbers of initiated charging operations. The number of ending charging operations per hour depends highly on the starting time of the charging operations $\left(t_{c, \text { init }}\right)$ and the charging durations $t_{c, \text { diff }}$. This interdependency is described implicitly in the following section.

\subsection{Charged energy}

Fig. 8 provides histograms of the charged energy and the SOC difference $S O C_{d i f f}$ for the data source which does not provide initial and end SOC values but the charged energy (few charged energy values over $60 \mathrm{kWh}$ are 

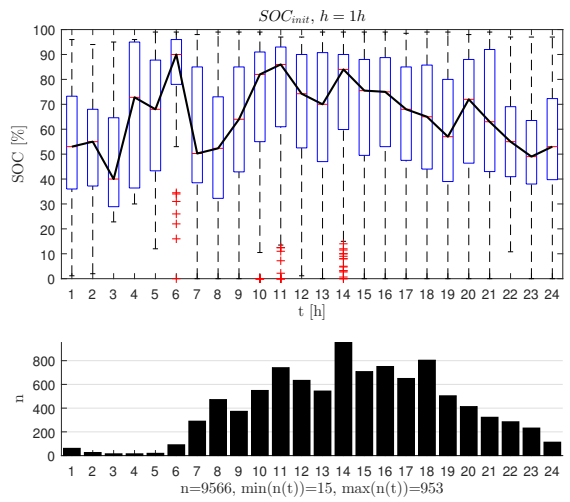

Figure 6: Hourly distribution of $S O C_{\text {init }}$ (box plot) and the corresponding number of starting charging operations for one day (histogram)

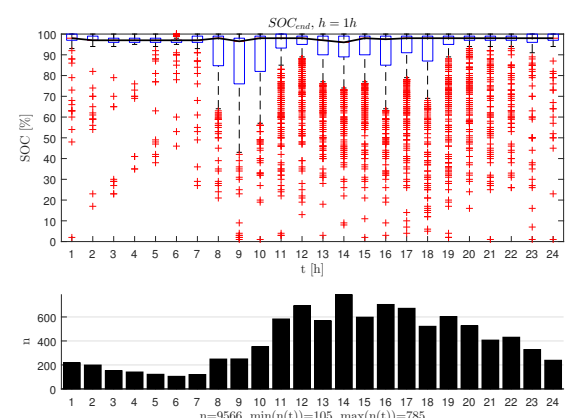

Figure 7: Hourly distribution of $S O C_{\text {end }}$ (box plot) and the corresponding number of ending charging operations for one day (histogram)

not shown in the diagram). The SOC difference has been calculated using the EV battery capacity, the charged energy and an assumed efficiency of $\eta=90 \%$. Most of the charging operations charge less than $20 \mathrm{kWh}$ due to the small battery capacity of most vehicles but also due to the fact that EV are charged with high initial SOC (indicated by the other studies).

The median of the charged energy, dependent on the hour of the charging start time, is highest in the early morning hours and lowest after noon. Detailed information on the dependency between charged energy and charging 

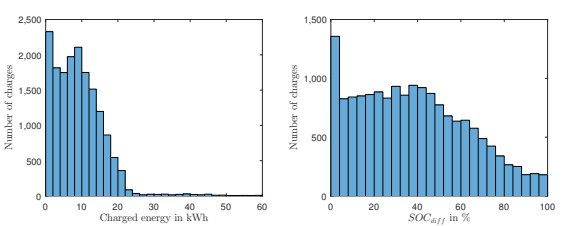

Figure 8: Histograms of charged energy and SOC difference for data sources without SOC values $(\mathrm{n}=16,604)$

duration can be found in the appendix.

\subsection{Number of parkings}

The distribution of the parking start $t_{p, \text { init }}$ over a day (c.f. fig. 9) shows similarities with the characteristics of the distribution of the charging times over the day $t_{c, \text { init }}$. However, the distribution of parking end times $t_{p, \text { init }}$ (departing EV) shows a slightly similar trend with a shifted peak to the afternoon. This reflects the fact that EV are more likely to depart and arrive during the day than during the night.

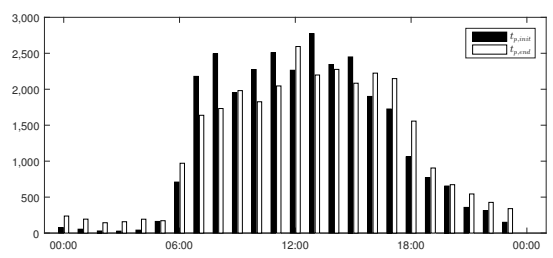

Figure 9: Number of parking start and end times over a day

\subsection{Parking and charging duration}

The evaluation of the parking durations in comparison with the charging durations is based on the data which covered all charging processes with information on charging and parking time $(n=6,278$ in total) and with parking durations smaller than seven days. The average charging process 
duration is longer when charging processes were started in the evening than when they were started in the morning. It can be observed that almost all vehicles are completely recharged at at the end of parking. The visible gray area in fig. 10 depicts the potential for shifting charging operations (load shifting). This shifting potential is highest for vehicles parked in the afternoon around 4 p.m. to 8 p.m. and during the night between around 11 p.m. to 3 a.m.

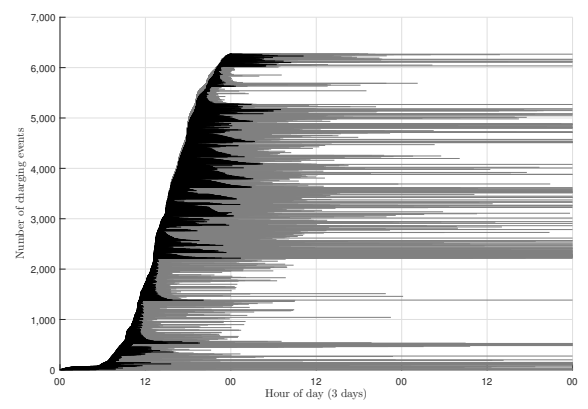

Figure 10: Charging durations ordered first by starting time and second by length (black) and the corresponding parking duration (gray, cut when greater than three days analogously ordered)

\section{Empirical load profiles}

This part provides an answer of the first research question of this paper. Empirical load profiles resulting from the EV charging characteristics are presented. These load profiles are time series of power values (usually with a resolution of a quarter of an hour). We solely use the CROME and iZeus charging operations $(n=9,395)$ as they provide the necessary information (without assumptions) on the SOC values at the start and the end of the charging operations. We first explain the applied methods for the creation 
of the load profiles. Subsequently we provide a standardization factor that allows to compare the load profiles of the different data sets. In the following we explain how we represented and approximated the active power charging curves. After this introducing information we present the empirical load profiles generated with the given data and with additional assumptions on maximal charging power and charging start times.

\subsection{Methods of load profile creation}

In this paper we use a direct and an indirect method to create load profiles. The choice of the method applied mainly depends on the underlying data. Both methods allow to produce load profiles for a given time frame. The direct method uses all data of each individual charging process. However, data may originate from different sources like time-dependent SOC, charging power logged by the battery management system of the vehicle or by the charging power outlet. To obtain the load profiles, the data is converted to active power time series with assumptions on charging losses. The indirect method requires information on start and end times of charging events as well as the corresponding (initial and final) SOC. With assumptions on the power and energy requirements during the charging processes a charging profile can be generated. When the data is used as input for the simulation model (explained in part 6), the empirical density functions (in contrast to compositions of continuous density functions (Dickert and Schegner, 2011) spanning the time frame of the load profile (usually of one day) are used. Significance of the data increases with a higher number of charging processes and is higher for the direct method due to conceptual reasons. The direct method requires measuring equipment in the vehicle or measuring equipment 
attached to the charging point. In contrast, the indirect method requires solely one charging data set per vehicle and charging type as well as values of three parameters per charge. The higher precision of the direct method may be used to validate the quality of generated data of the indirect method. The number of data records for the direct method exceeds the data records for the indirect method for more than one dimension. Characteristic and fixed active power charging curves of the EV are required by the indirect method and were used for the calculations of the load profiles described in this part. Despite the different data qualities the load profiles of the indirect and direct method compared in fig. 11 are similar. The curves are standardized load profiles, with a charged energy per day of $E(24 h)=4.44 \mathrm{kWh}$. In contrast to the direct method, the indirect method offers the advantage to insert different assumptions for the calculation of a load profile when data is not available or to simulate alternative scenarios (e. g. fast charging).

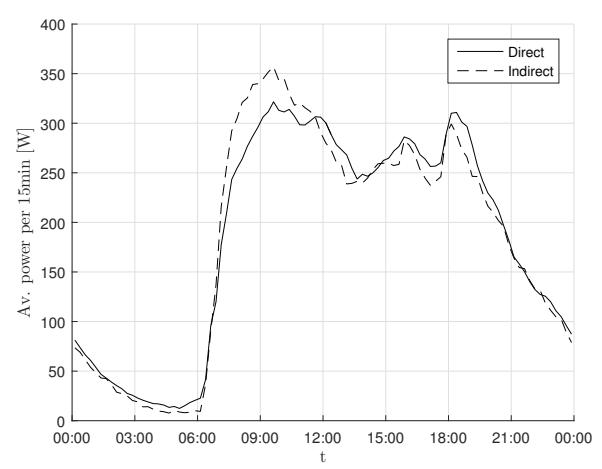

Figure 11: Comparison of standardized $\left(E_{24 h}=4.44 \mathrm{kWh}\right)$ load profiles for data edited with the indirect and direct method 


\subsection{Active power charging curves}

Active power charging curves (apcc) are characterized by the chronological sequence of charging power during the charging process of the EV. The indirect method requires knowledge of these curves to trace the course of charging. Fig. 12 depicts two empirical apcc (with a maximal active power of $3.7 \mathrm{~kW}$ ) of an EV, each equipped with a $20 \mathrm{kWh}$ lithium-ion battery, and their approximation. Charging of this battery technology is performed applying constant current constant voltage (CCCV) charging. The main charging period uses constant current charging which results in a nearly constant charging power until the final charging voltage is reached and the charging process switches to constant voltage charging with rapidly falling charging power. Due to different influences (e. g. ambient or internal cell temperature) this process may vary. This variation implies a reduction of the charging current during constant current charging. In order to generate load profiles we use approximations (linear for the constant part, exponentially decreasing for the non-constant part, cf. fig. 12) of representative measured charging curves for the different EV models of the studies. The measured values of the apcc are either tracked active power or deduced from SOC values. The two different measured values imply additional considerations of electricity losses. Active power $P_{a}$ is metered at the power outlet for the charging cable (outside the car). In this case all losses $P_{l}$ before battery are included and represent the gross electricity demand from grid. SOC is metered by the battery management system (BMS) and does not include charging losses $P_{l}$

before battery. With a nominal battery capacity $C_{n}$ the active power $P_{a}$ (demand from grid) can be calculated as follows. 


$$
S O C=\frac{\int_{0}^{t} P_{a}(t)-P_{l}(t) d t}{C_{n}}
$$

Main sources of losses are the inverter and the thermal management of the battery packs (Richardson et al., 2012). An inverter has an efficiency $\eta$ between $95 \%$ and $98 \%$. Different sources state various values for battery chargers ranging from $90 \%$ (Litzlbauer, 2010) to $97 \%$ (Schuster, 2009). Further efficiency values for thermal management are not given. For the creation of the apcc (from SOC values) we used an efficiency of $\eta=90 \%$.

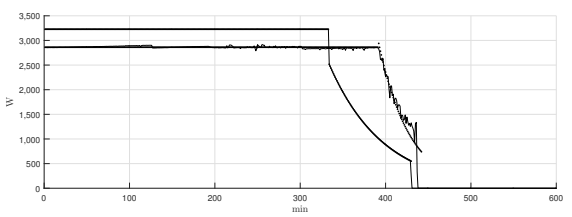

Figure 12: Empirical active power charging curves (lines) and their approximation (dots) for charging with a max. active power of $3.6 \mathrm{~kW}$ and a battery capacity of $20 \mathrm{kWh}$

\subsection{Standardization}

To compare the various data sets and assumptions and for the creation of standardized load profiles a standardization factor $a$ is introduced. $a$ is defined by the amount of charged energy of an EV that charges a SOC difference of $\overline{S O C}_{\Delta, h}, \overline{l p}_{h}$ times per observation period $h$ and has an efficiency of $\eta . W_{h}$ represents the average charged energy of an EV with an average battery capacity.

$$
\int_{0}^{h} a P(t) d t \stackrel{!}{=} W_{h}=\frac{\overline{l p}_{h} \bar{C} \overline{S o C}_{d i f f, h}}{\eta}=\frac{\overline{l p}_{h} \bar{E}}{\eta}
$$

The mean charging events per vehicle and per weekday at which a vehicle charges $\overline{l p}_{h=24 h}$ (c.f. fig. 3 and 4 ), the average SOC difference $\overline{S O C_{\Delta, h}}$ and 
Table 1: Nomenclature: Standardization of the load profiles

\begin{tabular}{ll}
\hline$h$ & unit of the observation period \\
$\overline{l p_{h}}$ & $\begin{array}{l}\text { av. number of charging operations in } \mathrm{h} \\
\bar{C}\end{array}$ \\
av. nominal battery capacity \\
charging efficiency $(0.9)$
\end{tabular}

the average charged energy $\bar{E}_{h=24}$ for the different weekdays are shown in table 2. Results of the MiD 2008 (Lenz et al., 2010) (c.f. part 2) indicate an average daily traveled distance of $39 \mathrm{~km}$. Together with an assumed average consumption of $12.49 \mathrm{kWh} / 100 \mathrm{~km}$ this results in an average energy demand $W_{h=24 h}$ of $5.412 \mathrm{kWh}\left(W_{h}=\frac{1}{\eta} \cdot 39 \mathrm{~km} \cdot 12.49 \mathrm{kWh} / 100 \mathrm{~km}\right.$, charged energy of $E=4.87 \mathrm{kWh}$ ). This value is slightly higher than the data of the CROME study suggests and about half as high as the average energy demand in the Get eReady study (c.f. table 2).

Table 2: Mean charging events per vehicle and per weekday at which a vehicle charges $\overline{l p}_{h}$, SOC difference $\overline{S O C}_{\Delta, h 024 h}$ and charged energy $\bar{E}_{h=24}$

\begin{tabular}{lccccccc} 
& Mon & Tue & Wed & Thu & Fri & Sat & Sun \\
\hline${\overline{l p_{h}}}^{a}$ & 1.69 & 1.66 & 1.78 & 1.85 & 1.86 & 1.71 & 1.46 \\
$\overline{l p_{h}}{ }^{b}$ & 1.36 & 1.31 & 1.28 & 1.33 & 1.42 & 1.14 & 1.21 \\
$\overline{S o}_{\text {diff }}$ & 25.6 & 25.9 & 26.9 & 25.5 & 26.2 & 22.9 & 26.2 \\
$E_{h}{ }^{d}$ & 10.6 & 9.2 & 9.4 & 9.5 & 9.3 & 10.8 & 11.5 \\
\hline
\end{tabular}

a: Data from CROME study

b: Data from Get eReady study

c: in \% for data from CROME study $(\bar{C}=16,94 k W h)$

d: in $k W h$ for data from Get eReady study 


\subsection{Load profiles}

The aggregated load profile of the 9,566 charging operations of the iZEUS and CROME study, for which $S O C_{\text {init }}$ and $S O C_{\text {end }}$ are known are presented in fig. 13. Within 1,061 days the EV have been charged during 9,395 charging operations with 41.051 MWh. This aggregated load profile is similar to the distribution ofthe starting times $\left(t_{\text {init }}\right)$ (c.f. histogram in fig. 6). When standardized (c.f. part 5.3) the resulting load curve may be used as standardized load profile of EV charging with a peak at $376.9 \mathrm{~W}$ at 6:15 p.m.

Fig. 13 shows the charging operations mentioned before distributed over a week according to the weekday of charging and the starting time $\left(t_{\text {init }}\right)$. Weekdays (Monday to Friday) show similar characteristics. The profiles of Saturday and Sunday show the same power level, however a different characteristic.

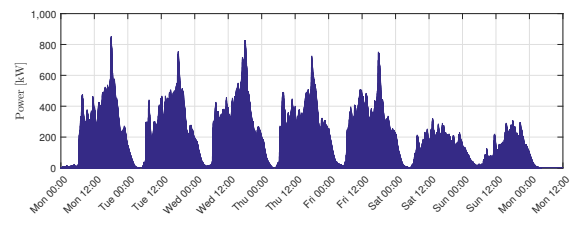

Figure 13: Load profile projected on a week $(\mathrm{n}=9,395)$

Differences in resulting charging load curve depending on the year of the fleet tests (2011 to 2014) may allow to derive EV drivers' behavior and their adaptation to the new technology. The load profiles in fig. 14 show the relative load profiles of the years for one day. For a better comparability of the periods the profiles were weighted with the total charged energy per year (821.3 MWh in 2014, 1,474.5 MWh in 2013, 155.13 MWh in 2012, 12.41 MWh in 2011). In the latter years of the fleet test users started to briefly charge 
in the early afternoon and to use night hours for longer charging operations which results in flatter load profiles.

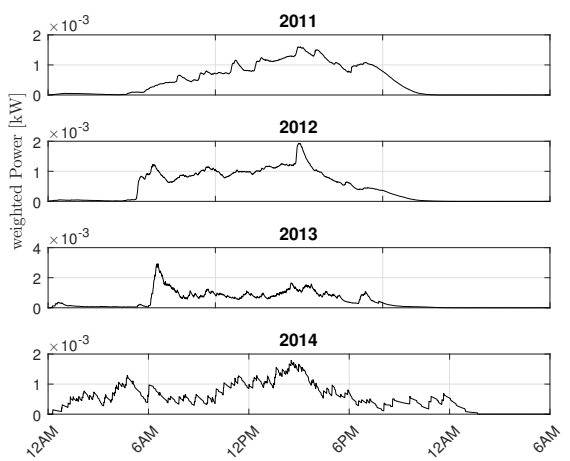

Figure 14: Load profiles for one day for the years 2011 to 2014 weighted with the total charged energy per year $(n=9,395)$

\subsection{Fast charging}

The previous analysis considered an actual maximum charging power of $3.7 \mathrm{~kW}$ of the EV. Solely few of the vehicles had the ability to be charged with a maximum charging power of $22 \mathrm{~kW}$. On the hypothesis that each charging event (except PHEV, c.f. below) is performed with a maximum charging power of $50 \mathrm{~kW}$ e. g. Chademo, (Schäuble et al., 2016a) the (standardized) load profiles change as depicted in fig. 15. For this analysis, charging operations of PHEV still have a maximal charging power of $3.7 \mathrm{~kW}$. For PHEV the relevance of fast charging is considerably lower due to their significantly smaller battery capacity (compared to BEV) and the available internal combustion engine (ICE). The individual charging processes were based on the approximation (c.f. part 5.2) of a measured CCCV charging profile with a maximum charging power of $50 \mathrm{~kW}$ for each vehicle model. The higher the maximum charging power, the shorter the charging duration. And, the 
higher are the similarities between charging power and starting times of the charging operations (correlation coefficients for $3.7 \mathrm{~kW}$ and $50 \mathrm{~kW}$ load profiles are 0.596 and 0.733). By shortening the individual charging time, the charging load decreases to nearly zero from 2:30 am to 5:30 am. Though, higher charging powers result in load fluctuations as well as distinct peaks.

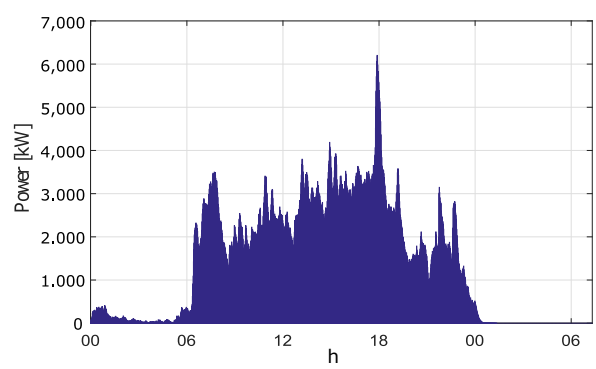

Figure 15: Synthetic load profile for one day with a maximum charging power of $50 \mathrm{~kW}$ $(\mathrm{n}=9,395)$

\subsection{Load shift potential}

Based on the hypothesis that the charging power is always adapted to the available charging time, the load profile changes significantly. Fig. 16 shows the (standardized) load profile under the assumption of an equally distributed charging power level that allows to cover the necessary amount of energy over the available charging duration for each individual charging operation. Assuming that all EV are applying this charging strategy results in a levelized load profile with higher minima and lower maxima.

In most cases, parking duration considerably exceeds charging duration which can be used for a controlled charging process. In the following, three different charging strategies (all with the actual maximum charging power of $3.7 \mathrm{~kW}$ or $22 \mathrm{~kW}$ ) are considered for the temporal distribution of the actual 


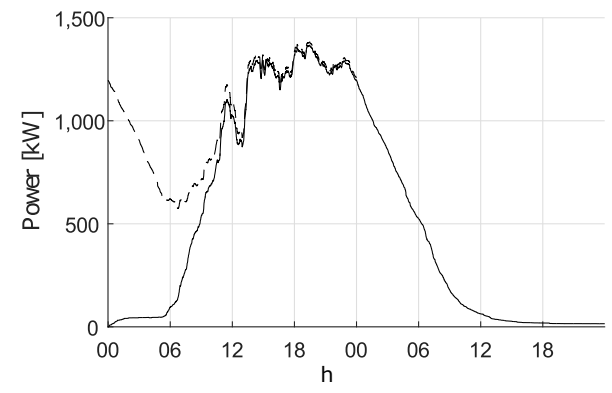

Figure 16: Load profile for one day with an equally distributed, individual maximum power rate (Dotted line shows the stacked profile for hours greater than $24 \mathrm{~h})(\mathrm{n}=9,395)$

charging time over the parking periods:

A. The charging operation starts immediately at the beginning of the parking period until a SOC equivalent to a range of $20 \mathrm{~km}$ is reached. The remaining SOC difference is charged at the very end of the parking period.

B. The entire parking duration minus five minutes (This value corresponds to the period in which about $75 \%$ of all charging operations have been initiated after having parked the car) is used to charge at a constant charging power. In this charging strategy the charging power is adapted to the available parking time (s. part 5.6).

C. The charging operation is performed at the end of the parking period so that charging end and departure of the following trip match.

Fig. 17 shows the weighted load profiles of the three different strategies $(\mathrm{n}=6,115)$ and the basic load profile $(\mathrm{n}=9,395)$ in comparison. Parking times were not available for all of the charging operations with SOC values. This is the reason why the profiles have been weighted with the total charged energy. Solely few initial SOC are lower than the predefined equivalent of 
$20 \mathrm{~km}$ range, resulting in a similar curve for strategies A and C. Differences around midnight may be explained by differences in the number of departing and parked vehicles. As explained before, the load profile for strategy B is similar to the balance of departing and parked vehicles and results in a levelized curve. If there are more vehicles on the road than there are parked, the charging load decreases.

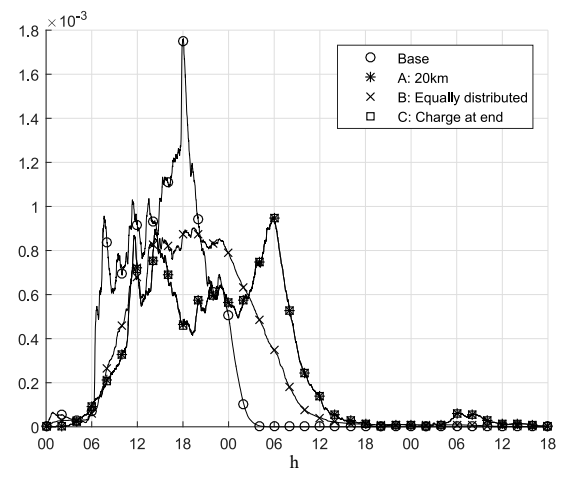

Figure 17: Load profiles of different charging scenarios weighted with the total charged energy

\section{Synthetic load profile generation}

This part intends to answer the second and third research question of this paper. The development and results of the simulation model for generation of standardized, daily load profiles of EV charging are presented. In a first step main model inputs, parameters and outputs are highlighted. Subsequently the simulation process is explained in detail. The thereby simulated load profiles are subsequently presented before scenarios for the maximum power rate are described and a discussion of simulation runs considering these scenarios is presented. The simulation was developed in Matlab ${ }^{\circledR}$ R2015b in connection with a MySQL Database. 


\subsection{Model input}

The data originating from the e-mobility field tests described in section 3 of this paper provide a statistically relevant number of data sets with charging operations which are used as input for the simulation model. Using the empirical model parameters, the developed model algorithm simulates a load profile $c$ for a given period $P$ and a given number of $\mathrm{EV} n$. The simulation model uses EV parameters like capacity $C_{e v}$ and an approximation of the apcc that depends on the maximal charging power as well as on the duration and parameters of the constant and nonlinear power part. The number of charges per $\mathrm{EV} \xi_{d}$ and $P$, initial SOC level $S O C_{i n i t}$ dependent on the charging start time, final SOC levels $S O C_{n}$ and charged energy $E_{c h}$ (dependent on the available empirical data) are used to calculate the load profile.

\subsection{Model process}

Fig. 18 gives an overview on the following model process.

1. Given a predefined number of EV $n$ and a max charging power $p_{\max }$ the model simulates a charging profile based on the presented empirical emobility data over a predefined period $P$ which may either be a specific day of the week, a general day or an entire week (fig. 18:1).

2. The EV characteristics $\left(C_{e v}\right.$ and $\left.a p c c_{e v}\right)$ are drawn randomly from the $30 \mathrm{EV}$ models of the studies (fig. 18:2). The apcc is dependent on the either predefined or randomly drawn maximum charging power $p_{\max }$. When not predefined $p_{\max }$ is drawn from the probability distributions of the scenarios described in part 6.4 (s. table 4). 
Table 3: Model nomenclature

\begin{tabular}{ll}
\hline Input & \\
$P$ & Number of EV \\
$P$ & Observation period \\
$p_{\text {max }}\left(t_{\text {init }}\right)$ & Max. charging power in $t_{\text {init }}{ }^{a}$ \\
\hline Parameter & \\
$C_{e v}$ & EV battery capacity in $\mathrm{kWh}$ \\
$a p c c_{e v}$ & apcc of the EV \\
$\xi_{d}$ & Average number of charges ${ }^{b}$ \\
$\xi_{d}(n)$ & Number of charges (rand. Var.) \\
$t_{\text {init }}=t_{p, \text { init }}$ or $\left.t_{c, \text { init }}\right)$ & Start time of charging \\
$S O C_{\text {init }}\left(\right.$ hour $\left.\left(t_{c, \text { init }}\right)\right)$ & Initial SOC in kWh \\
$S O C_{\text {end }}$ & Final SOC value in $\mathrm{kWh}$ \\
$E_{c h}$ & Charged energy in $\mathrm{kWh}$ \\
\hline Output & \\
$t_{\text {end }}$ & Charging end time \\
$c_{\text {op }}(t)$ & Number of charging EV \\
$c$ & Load profile \\
\hline
\end{tabular}

a: Input for case I, parameter for case II (c.f. fig. 18:1 and 5a/5b)

b: Divided into $\xi_{d, e}$ for data with information on initial and final SOC values and and $\xi_{d, s}$ for data with information on the charged energy without knowledge of the SOC

3. Subsequently the number of charges $\xi_{d}$ per day and $n \mathrm{EV}$ for each day (either one or seven) of the period $P$ is determined (fig. 18:3, c.f. also fig. 4). This may be the calculated average values of part 4.1 and table $2\left(\xi_{d}=\overline{l p}_{h=24 h}=1.5378\right)$ or a random variable drawn from the empirical distribution of charges for $n \mathrm{EV} \xi_{d}(n)$.

4. Because of the heterogeneous database (c.f. part 3) $\xi_{d}$ is divided proportionally to the data sources' size into $\xi_{d, e}$ and $\xi_{d, s}$ (fig. 18:4). The data source is divided into two parts: one with information on initial and final SOC values (represented by $\xi_{d, s}$ ) and another that solely pro- 
vides information on the charged energy without knowledge of the SOC (represented by $\xi_{d, e}$ ).

5. After the initialisation of the model loop for each $\xi_{d}$ the independent initial charging time is drawn from the empirical data (fig. 18:5a and $5 b)$.

6. For $\xi_{d, s}$ charges the initial SOC is drawn dependent on the hour of the initial charging time (fig. 18:6, c.f. fig 6 and part 4.4).

7. Subsequently, a final SOC value is drawn independently (c.f. fig 7 and part 4.4) for all $\xi_{d}$ charges (fig. 18:7).

8. For all $\xi_{d, s}$ drawn SOC values are checked for consistency $\left(S O C_{\text {end }} \geq\right.$ $S O C_{\text {init }}$ ), if inconsistent another end SOC value is drawn (fig. 18:8).

9. With EV capacity, given initial and end SOC the energy to charge can be calculated $E_{c h}=$ $C_{e v}\left(S O C_{\text {end }}-S O C_{\text {init }}\right)$ for all $\xi_{d, s}$ (fig. 18:9b). In contrast, for all $\xi_{d, e}$ the energy to charge is drawn from the empirical data dependent on the hour of initial charging time (fig. 18:9a).

10. If the drawn end SOC value is less than $100 \%$ the apcc has to be cut off at the end. Dependent of $S O C_{\text {end }}$ the cut may occur in the linear or nonlinear part of the apcc. The $S O C_{\text {init }}$ (implicitly through $E_{c h}$ ) determines if the apcc front part has to be cut (fig. 18:10, c.f. fig. 12).

11. With $t_{\text {init }}$ and a trapezoidal numerical integration over the cut apcc the charging end time $t_{\text {end }}$ is determined (fig. 18:11).

12. The following step performs the check if for any timestep t (granularity: minutes) of $P$ the number of charging vehicles $c_{o p}(t)$ is less than the number of all $\mathrm{EV} n$ (fig. 18:12). If this is 
true the last charging operation is skipped and the loop starts with another charging starting time (fig. 18:3a or b).

13. Otherwise, the iterator is incremented an the calculated and trimmed apcc is added to the load profile $c$ (fig. 18:13).

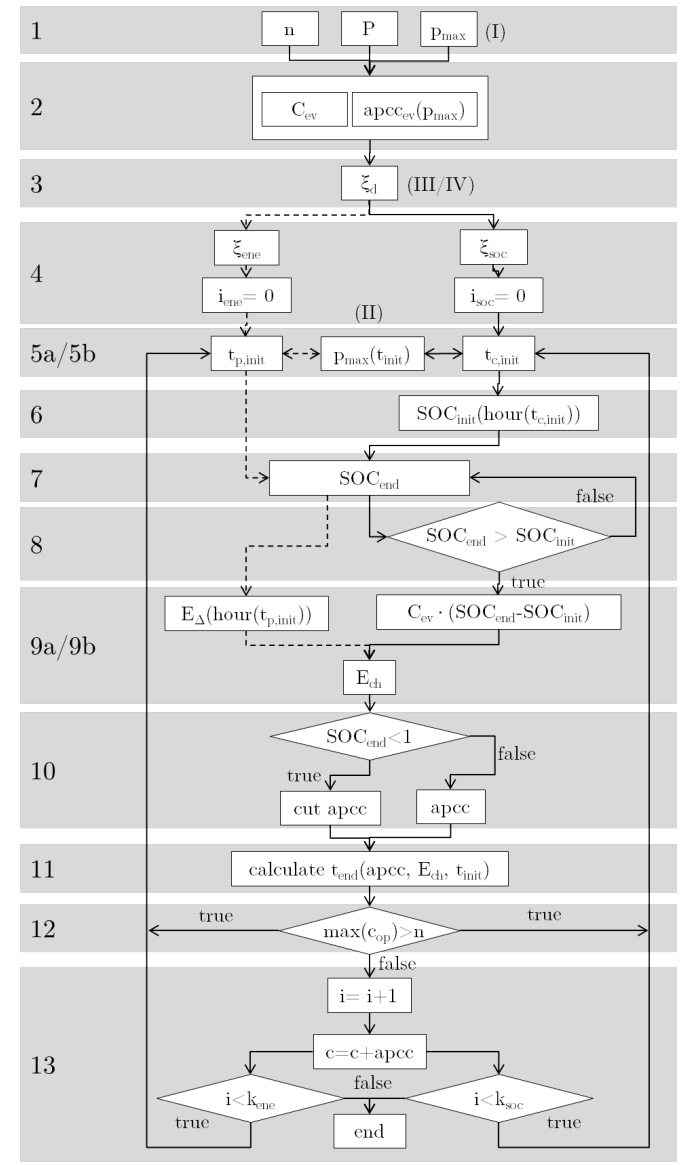

Figure 18: Model process

\subsection{Simulated load profiles}

Dependent on the input and model parameter variations a multitude of different simulation results can be generated. A collection of simulation runs 
is made available online: The collection of the simulation runs including all parameters can be downloaded from Schäuble et al. (2017).

Fig. 19 and fig. 20 show the spectra of 250 simulated load profiles of charging operations of $100 \mathrm{EV}$ that charge at least once every day with $p_{\max }$ $=3.6 \mathrm{~kW}$ (shown in fig. 19) and $p_{\max }=50 \mathrm{~kW}$ (shown in fig. 20) using the mean number of charging events per vehicle and per day (154). For $p_{\max }=3.6 \mathrm{~kW}$ the spectrum stays below $150 \mathrm{~kW}$ and the mean (light area) shows a characteristic bell-shaped profile that extends over a large part of the following day. When stacking the mean of the following day on the mean of the first day (dark area) the resulting mean profile shows a minimum at around 5 a.m. The spectrum for the simulations with $p_{\max }=50 \mathrm{~kW}$ (fig. 20) however show peaks up to $300 \mathrm{~kW}$. Charging activities do not extend to the following day which leads to a low electricity demand during the night (midnight to 4 a.m.). Fig. 21 exemplary depicts three individually simulated load profiles for $100 \mathrm{EV}$ that charge at least once every day with a maximum charging power of $p_{\max }=3.6 \mathrm{~kW}$ using the mean number of charging events per vehicle and per weekday.

\subsection{Scenarios for the maximum power rate}

As there are different types and modes of charging infrastructure for different areas of public and private locations, the parking locations may serve as indicator for the maximum charging power rate $p_{\max }$. The German National Electric Mobility Platform (NPE) identified three main locations for EVSE (Nationale Plattform Elektromobilität (NPE) (2014)) and forecasts the number of charging points for the year 2020. Based on these projections on the relative numbers of EVSE, probabilities are set for the use of a 


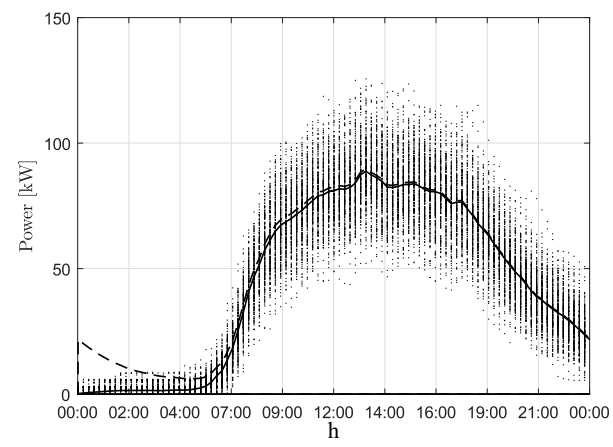

Figure 19: Spectrum of 250 simulated load profiles of charging operations of $100 \mathrm{EV}$ that charge at least once every day with $p_{\max }=3.6 \mathrm{~kW}$ using the mean number of charging events per vehicle and per day $\left(\xi_{d}=1.54\right)$, the mean (solid black line) and the mean of the following day stacked on the mean of the first day (dotted black line).

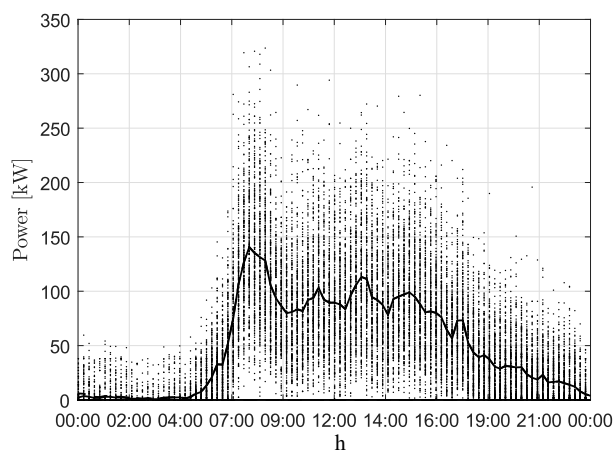

Figure 20: Spectrum of 250 simulated load profiles of charging operations of $100 \mathrm{EV}$ that charge at least once every day with $p_{\max }=50 \mathrm{~kW}$ using the mean number of charging events per vehicle and per day $\left(\xi_{d}=1.54\right)$, the mean (solid black line) and the mean of the following day stacked on the mean of the first day (dotted black line).

particular $p_{\max }$ dependent on the parking location (Scenario P0). The relative numbers (probabilities) of $p_{\max }$ are combined with the probability of the parking location that depends on the time of day (c.f. fig. 5) which results in probabilities for different maximum charging rates depending on the time of day (with respect to the chosen resolution). Categories for the parking locations are semipublic (e. g. supermarkets), companies (co.), curbside and 


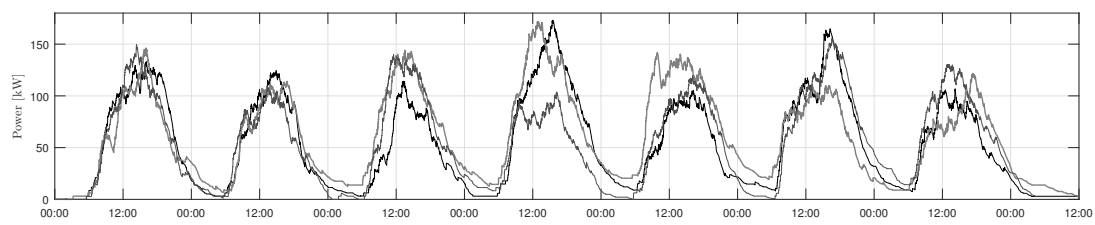

Figure 21: Three simulated load profiles over a week, starting on Monday, for $100 \mathrm{EV}$ that charge at least once every day with $p_{\max }=3.6 \mathrm{~kW}$ using the mean number of charging events per vehicle and per weekday (Number of charges: Mon 154, Tue 151, Wed 158, Thu 163, Fri 157, Sat 153, Sun 144)

private (priv.) sites. Two comparative projections (Sc. P1 and P2) with higher shares of faster $p_{\max }$ are taken into consideration additionally to illustrate the influence of the use of different charging power rates. Table 4 shows a comparison of the three scenarios.

\begin{tabular}{cccccc}
\multicolumn{6}{c}{ Table 4: Scenarios for probabilities of $p_{\max }$ in 2020} \\
\hline Sc. & {$[\mathrm{kW}]$} & Semipub. & Curbs. & Co. & Priv. \\
\hline \multirow{4}{*}{ P0 } & 3.7 & 0 & 0.9 & 1 & 1 \\
& 22 & 0.94 & 0.1 & 0 & 0 \\
& 50 & 0.06 & 0 & 0 & 0 \\
\hline \multirow{4}{*}{ P1 } & 3.7 & 0.4 & 0.4 & 0.7 & 0.79 \\
& 22 & 0.5 & 0.3 & 0.2 & 0.2 \\
& 50 & 0.1 & 0.3 & 0.1 & 0.01 \\
\hline & 3.7 & 0.04 & 0.05 & 0.55 & 0.65 \\
P2 & 22 & 0.90 & 0.2 & 0.40 & 0.30 \\
& 50 & 0.06 & 0.75 & 0.05 & 0.05 \\
\hline
\end{tabular}

According to the probabilities given in Table 4, the simulated standardized load profiles show different proportions of the three maximum charging power rates $(3.6 \mathrm{~kW}, 22 \mathrm{~kW}$ and $50 \mathrm{~kW})$ dependent on the chosen scenario. The profiles show similar characteristics compared to the profiles of the empirical data analysis with the assumtion on the maximum charging power 
$p_{\max }$. This may lead to the conclusion that the distribution of the number of initial charging operations has the greatest impact on the load curve characteristics. Though, influence of the number of higher charging power rates and SOC difference per charge are less important.

\section{Discussion and conclusion}

Despite the following comparison of simulated and empirical load profiles that provides an evaluation and valuation of the attained results, a final validation remains difficult as the underlying data sources differ considerably. Additionally filtering, processing and usage of this data has to be reviewed critically as several assumption are included in these processes.

\subsection{Validation}

The simulated EV load profiles in Pasaoglu et al. (2013) generally show similar characteristics to the simulations of this work, e. g. the working days differ from the weekend and and all have several power peaks across the day. The uncontrolled commercial public charging scenario of Qian et al. (2011) however shows a less distinct load in the afternoons compared to our results. The comparison of the spectra of the EV load profiles of Litzlbauer (2010) (based on data of Kirnbauer et al. (2007)) and our results show similar profiles during the evening and the night (from 6 p.m. to 8 a.m.) though diverge significantly during the day. The reason for this difference may primarily be due to the different groups of EV users our simulations are based on. A detailed description of the EV user groups - mainly commercial fleet users - can be found in literature. According to Ensslen et al. (2016a) $75 \%$ of the organizations participating in the Get eReady fleet test were small 
and medium-sized companies with up to 250 employees. The study presents fleet managers answers on relevance and willingness to pay for e-mobility services. Ensslen et al. (2016b) characterizes two different case studies of EV adoption in Get eReady. The first case study focuses on criteria relevant for the participating organizations' car purchase decisions by analyzing survey data. The second case study characterizes the participating organizations by analyzing protocols from sales activities. Besides technical and juridical aspect of the CROME project, Schäuble et al. (2016b) describe the EV users participating in the field test based on data originating from standardized surveys and guided interviews. Ensslen et al. (2013) compare EV user acceptance between French and German participants in the CROME project as well as between participants living in rather urban and rather rural areas. Ensslen et al. (2016c) compare the CROME field trials participants sociodemographic as well as attitudinal characteristics with the characteristics of participants of five other field trials. According to the results presented in this study EV adopters tend to have a high level of income, have more than one car and travel high distances, not necessarily by car. Possibilities to experience EV (e. g. by test drives) seem supportive to EV adoption. Specific information on the user characteristics of the iZEUS field test however are not published. When comparing the results of this paper with accompanying research of the project VLOTTE described in Schuster et al. (2010) it can be noted that the load profile has a low difference between the global maximum and minimum. The charged amount of energy per EV and day is significantly higher $(11.8 \mathrm{kWh})$ which may be caused by longer average distances. However similar patterns can be identified: a strong increase in the 
load in the morning from 6 a.m. to 9 a.m. and local maxima at 2 a.m. The load profiles simulated in Gozel et al. (2012) based on data of the Ultra Low Carbon Vehicle Demonstrator Programme (Everett et al., 2011) show different characteristics. Peaks occur between 9 p.m. and midnight and around 6 a.m. The EV load profile from EV charged at work of Gozel et al. (2012) shows similarities with maxima around 2 p.m. and 6 a.m. The comparison of the different simulated load profiles highlights the necessity of a distinctive analysis taking into account user group, location and maximum charging power.

In order to provide an answer to the the first research question on how EV mobility and charging data should be processed to create descriptive EV load profiles and what the characteristics of these EV load profiles are, the analysis and prepossessing of the inhomogeneous EV mobility and charging data of the studies had been an important task within the process of creating meaningful descriptive EV load profiles. First a consequential data basis had to be created, that subsequently served as main input data for the analysis of the characteristics of EV load profiles. Data characteristics are presented for all fleets in general (e. g. charging processes per month and weekdays etc.) and their evolution in time. However, this data has to be looked at in detail to understand the characteristics of individual charging events (e.g. time of charging, location, state of charge, etc.). The empirical load profiles derived integrate all the characteristics (using active power charging curves) and present them in single load profiles. The fact that we provided a detailed description of the characteristics of the input data that served to build these synthetic load profiles allows to have a better understanding of these 
synthetic load profiles when they are used as input parameters in further analysis. However, due to the specific data formats available in the three field tests we can only generalize our approach to a certain extent. In order to answer the second research question on how EV load profiles can be simulated using empirical charging data, we further analyzed the pre-processed data to derive simulated synthetic load profiles of the population considered. This simulation model allows to create a multitude of characteristic and synthetic EV load profiles that may serve as input parameters for further analyses. Finally, we provided an answer to the third research question treating the characteristics of the simulated EV load profiles by analyzing three different scenarios concerning charging power rates at different locations. We observed that the distribution of the number of initial charging operations has the greatest impact on the load curve characteristics. It has to be noted the simulated load profiles are based on data originating from EV that were predominantly used as pool vehicles in organizations. Possibilities for generalizations, particularly concerning potential claims for representativeness, are with these data limited.

\subsection{Critical appraisal}

Prior to processing, the data had to be checked for plausibility. If possible data sets were corrected based on assumptions. This may lead to records that partially lack information (c.f. part 3.4). E. g. a filtering of the measured SOC differences was performed. All values greater $100 \%$ of the corresponding charging process were ignored. The same applies to incomplete (e. g. solely initial SOC value) or inconsistent records. The parking duration was not given explicitly for all of the data records and had to be defined as the 
duration between two trips, when necessary. A trip start during an ongoing charging process was considered as data error. The corresponding parking duration was then omitted. Repeated charging during parking has been aggregated to one (the first) charging operation. As the fleet studies took place in a limited geographic scope, the data base consists of charging events that solely occurred at specific locations. In addition to that the data collection methods differed between the field trials. A generalization of the models is not per se possible, also due to the limited size of the recorded charging events. The conclusions drawn should consider these limitations.

\subsection{Outlook}

The comparison of this paper's load profiles with results presented by other authors (c.f. part 7) shows similar patterns in general. However, assumptions of other authors lead to different results. This reveals challenges that have to be addressed in future. A detailed analysis of the differences between charging locations (e. g. home, work, public EVSE) may lead to important information on the geographical load distribution.

Concluding, the detailed description of EV load profiles on the basis of a comprehensive data base in this paper provides precise projections of the electricity demand of this new technology and helps to better integrate EV into future energy systems.

\section{Acknowledgements}

This work was supported by the the German Federal Ministry for Eco-

nomic Affairs and Energy, the German Federal Ministry of Transport and Digital Infrastructure in Germany and the French program "Investissements 
davenir programme vhicule de futur" [grant numbers 01ME12002, 16SBW020E and 01ME12013]. The following institutes of the KIT and project partners provided help during the research: AIFB, FAST, IEH, IfV and ZAR as well as Porsche AG, PSA Peugeot Citron, Renault, Adam Opel AG, Daimler AG and Bosch Software Innovations.

\section{References}

Ahn, C., Li, C.-T., and Peng, H. (2011). Optimal decentralized charging control algorithm for electrified vehicles connected to smart grid. Journal of Power Sources, 196(23):10369-10379.

Babrowski, S., Heinrichs, H., Jochem, P., and Fichtner, W. (2014). Load shift potential of electric vehicles in europe. Journal of Power Sources, 255:283-293.

BMVBS (2010). German Mobility Panel (MOP) (in German: Deutsches Mobilitätspanel). Technical report, Bundesministeriums für Verkehr, Bauund Stadtentwicklung (BMVBS). Institut für Verkehrswesen, KIT.

Corchero Garcia, C., Gumara Ferret, R., Cruz Zambrano, M., Sanmarti, M., Gkatzoflias, D., Dilara, P., Drossinos, I., and Donati, A. (2014). Data Collection and Reporting Guidelines for European electro-mobility projects. Technical report, Luxembourg.

Dickert, J. and Schegner, P. (2011). New approaches for modeling of synthetic loads for the planning and operation of smart grids (in German: Neue Ansätze der Modellierung synthetischer Lastgänge für Planung und 
Betrieb von Smart Grids). pages 1-6, Berlin Offenbach. Internationaler ETG-Kongress, VDE-Verlag.

Drude, L., Pereira Junior, L. C., and Rüther, R. (2014). Photovoltaics (PV) and electric vehicle-to-grid (V2G) strategies for peak demand reduction in urban regions in Brazil in a smart grid environment. Renewable Energy, $68(0): 443-451$.

E-mobility Graz (2013). Status report of the E-Mobility model region Graz (in German: Statusbericht der E-Mobilitäts modellregion Großraum Graz). Technical report, Graz, Austria.

Ensslen, A., Gnann, T., Globisch, J., Plötz, P., Jochem, P., and Fichtner, W. (2016a). Willingness to pay for e-mobility services: a case study from Germany. In Proceedings of Karlsruhe Service Summit Workshop, pages $1-14$.

Ensslen, A., Jochem, P., and Fichtner, W. (2013). Experiences of EV users in the French-German context. In 2013 World Electric Vehicle Symposium and Exhibition (EVS27), pages 1-12.

Ensslen, A., Kuehl, N., Stryja, C., and Jochem, P. (2016b). Methods to Identify User Needs and Decision Mechanisms for the Adoption of Electric Vehicles. Session 1F: Understanding EV Consumers. Proceedings of EVS29 Symposium. Montral, Quebec, Canada, June 19-22, 2016.

Ensslen, A., Paetz, A.-G., Babrowski, S., Jochem, P., and Fichtner, W. (2016c). On the road to an electric mobility mass markethow can early 
adopters be characterized? In Markets and Policy Measures in the Evolution of Electric Mobility, pages 21-51. Springer.

Everett, A., Burgess, M., and Walsh, C. (2011). Initial findings from the ultra low carbon vehicle demonstrator programme. Technical report, Technology Strategy Board.

EVI-IEA (2016). Global EV Outlook. Technical report, Paris, France.

Gozel, T., Ochoa, L. N., and Mancarella, P. (2012). Report for deliverable 1.5 'review of available data and techniques to model new loads and der'. Technical report, The University of Manchester, Manchester, UK.

Habib, S., Kamran, M., and Rashid, U. (2015). Impact analysis of vehicle-togrid technology and charging strategies of electric vehicles on distribution networks - A review. Journal of Power Sources, 277(0):205 - 214.

Hahn, T., Schönfelder, M., Jochem, P., Heuveline, V., and Fichtner, W. (2013). Model-based quantification of load shift potentials and optimized charging of electric vehicles. Smart Grid and Renewable Energy, 04(05):398-408.

Hildermeier, J. (2016). Which role should the electric car play in Europe's cities? An analysis of publicly funded demonstration projects 20072013. International Journal of Automotive Technology and Management, 16(1):90.

Kieckhäfer, K., Wachter, K., and Spengler, T. S. (2016). Analyzing manufacturers' impact on green products' market diffusion - the case of electric vehicles. Journal of Cleaner Production. doi:10.1016/j.jclepro.2016.05.021. 
Kirnbauer, R., Matiasek, F., and Spiegel, T. (2007). Transport in Figures (in German: Verkehr in Zahlen). Technical report, Bundesministerium für Verkehr, Innovation und Technologie, Vienna, Austria.

Lenz, B., Nobis, C., Köhler, K., Mehlin, M., Follmer, R., Gruschwitz, D., Jesske, B., and Quandt, S. (2010). Mobility in Germany (in German: Mobilität in Deutschland). Technical report, Bonn and Berlin, Germany.

Leurent, F. and Windisch, E. (2011). Triggering the development of electric mobility: a review of public policies. European Transport Research Review, 3(4):221-235.

Linssen, J., Birnbaum, U., and Markewitz, P. (2009). Potential assessment of the use of electric vehicles in Germany (in German: Potenzialabschätzung zum Einsatz von Elektrofahrzeugen in Deutschland). pages 1-7.

Litzlbauer, M. (2010). Creation and modeling of stochastic charging profiles of mobile energy storage (in German: Erstellung und Modellierung von stochastischen Ladeprofilen mobiler Energiespeicher). 11. Symposium Energieinnovation Graz, Austria, pages 1-14.

Loisel, R., Pasaoglu, G., and Thiel, C. (2014). Large-scale deployment of electric vehicles in Germany by 2030: An analysis of grid-to-vehicle and vehicle-to-grid concepts. Energy Policy, 65:432-443.

Mills, G. and MacGill, I. (2014). Potential power system and fuel consumption impacts of plug in hybrid vehicle charging using australian national electricity market load profiles and transportation survey data. Electric Power Systems Research, 116:1-11. 
Nationale Plattform Elektromobilität (NPE) (2014). Progress report 2014 on the market preparation (in German: Fortschrittsbericht 2014-Bilanz der Marktvorbereitung). Technical report, Berlin, Germany.

Pasaoglu, G., Thiel, C., Martino, A., Zubaryeva, A., Fiorello, D., and Zani, L. (2013). Projections for electric vehicle load profiles in europe based on travel survey data. Technical report, Luxembourg.

Qian, K., Zhou, C., Allan, M., and Yuan, Y. (2011). Modeling of load demand due to ev battery charging in distribution systems. IEEE Transactions on Power Systems, 26(2):802-810.

Richardson, P., Flynn, D., and Keane, A. (2012). Local versus centralized charging strategies for electric vehicles in low voltage distribution systems. IEEE Transactions on Smart Grid, 3(2):1020-1028.

Schäuble, J., Balaban, S., Krasselt, P., Jochem, P., Özkan, M., SchellhasMende, F., Fichtner, W., Leibfried, T., and Raabe, O. (2016a). Comparative study of system charges for fast charging of electric vehicles (in German: Vergleichsstudie von Systemansätzen für das Schnellladen von Elektrofahrzeugen) . Technical report, Karlsruhe, Germany.

Schäuble, J., Jochem, P., and Fichtner, W., editors (2016b). Cross-border Mobility for Electric Vehicles: Selected results from one of the first crossborder field tests in Europe. KIT Scientific Publishing, Karlsruhe, Germany. Doi: 10.5445/IR/1000053148.

Schäuble, J., Kaschub, T., Ensslen, A., Jochem, P., and 
Fichtner, W. (2017). Collection of the simulation runs. https://www.iip.kit.edu/english/3559.php.

Schuster, A. (2009). Battery or hydrogen storage in electric vehicles (in German: Batterie- bzw. Wasserstoffspeicher bei elelektrischen Fahrzeugen) . In Schuster, A., editor, 6. Internationale Energiewirtschaftstagung an der TU Wien, pages 1-20.

Schuster, A., Leitinger, C., and Brauner, G. (2010). Accompanying research at the TU Vienna in VLOTTE (in German: Begleitforschung der TU Wien in VLOTTE). Technical report, Technische Universität Wien, Vienna, Austria.

Smart, J., Powell, W., and Schey, S. (2013). Extended range electric vehicle driving and charging behavior observed early in the ev project. In SAE 2013 World Congress $\&$ Exhibition, SAE Technical Paper Series. SAE International400 Commonwealth Drive, Warrendale, PA, United States.

Valentine, K., Temple, W. G., and Zhang, K. M. (2011). Intelligent electric vehicle charging: Rethinking the valley-fill. Journal of Power Sources, 196(24):10717-10726.

Wieland, T., Reiter, M., Schmautzer, E., Fickert, L., Fabian, J., and Schmied, R. (2015). Probabilistic method for modeling the charging of electric vehicles by means of measured data of electrical charging stations - Load analyzes of charging stations taking into account the location for the planning of electric power networks (in German: Probabilistische Methode zur Modellierung des Ladeverhaltens von Elektroautos anhand gemessener 
Daten elektrischer Ladestationen - Auslastungsanalysen von Ladestationen unter Berücksichtigung des Standorts zur Planung von elektrischen Stromnetzen). e ES i Elektrotechnik und Informationstechnik, 132(3):160167.

Windisch, E. (2014). Driving electric? A financial assessment of electric vehicle policies in France. PhD thesis, Paris, France.

\section{Appendix}

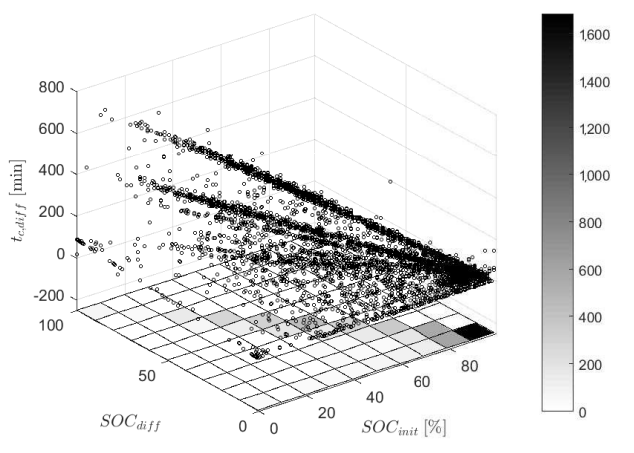

Figure 22: Interdependency of $S O C_{\text {init }}, S O C_{\text {diff }}$ and $t_{c, \text { diff }}$ (scattered points) in comparison with the number of observed charging operations (grid)

Figure 22 shows the interdependency of SOC at charging start $\left(S O C_{\text {init }}\right)$, charged SOC $\left(S O C_{d i f f}=S O C_{e n d}-S O C_{\text {init }}\right)$ and charging duration in minutes

$\left(t_{c, \text { diff }}=t_{c, \text { end }}-t_{c, \text { init }}\right)$. It can be observed that most of the charging operations end at a high $S O C_{\text {end }}\left(S O C_{\text {end }} \geq 90 \%\right.$ for $79 \%$ of all charging operations) and start with a high $S O C_{\text {init }}$ (cf. box plot of figs. 6 and 7) which results in small $S O C_{\text {diff }}\left(S O C_{\text {diff }} \leq 10 \%\right.$ for $37 \%$ of all charging 
operations). The charging duration $t_{c, \text { diff }}$ linearly correlates negative with the SOC at charging start $S O C_{\text {init }}$. The linear coefficients are the different charging power level $p$ during the charging operation (mainly about 8, 4.5 and $3.5 \% \mathrm{SOC}$ per min). With increasing $S O C_{\text {init }} S O C_{\text {diff }}$ decreases in total by definition. However, the relative value of $S O C_{\text {diff }}$ (corresponding to $100-S O C_{\text {init }}$ which is the amount to fully charge the EV) does not depend significantly on $S O C_{\text {init }}\left(r^{2}=0.0104\right)$. 